\title{
Erratum to: Identification of Interaction Pressure Between Structure and Explosive with Inverse Approach
}

\author{
S. Xu • V. Tiwari $\cdot$ X. Deng $\cdot$ M.A. Sutton $\cdot$ W.L. Fourney
}

Published online: 3 March 2011

(C) Society for Experimental Mechanics 2011

Erratum to: Experimental Mechanics

DOI 10.1007/s11340-010-9390-y

The department for author, W.L. Fourney was listed incorrectly. Here is the correct information:

W.L. Fourney, (SEM member)

Department of Aerospace Engineering, University of Maryland, College Park, MD 20742, USA

The online version of the original article can be found at http://dx.doi. org/10.1007/s11340-010-9390-y.

S. Xu $(\bowtie)$

Department of Mechanical Engineering,

Georgia Southern University,

Statesboro, GA 30458, USA

e-mail: shaowenxu@georgiasouthern.edu

V. Tiwari $\cdot$ X. Deng $\cdot$ M.A. Sutton (SEM member)

Department of Mechanical Engineering,

University of South Carolina,

Columbia, SC 29208, USA

W.L. Fourney (SEM member)

Department of Aerospace Engineering, University of Maryland,

College Park, MD 20742, USA 